\title{
Work Productivity and Activity Impairment in Colorectal Cancer Patients Treated with Capecitabine
}

\author{
Giulia Malaguarnera $^{1 *}$, Manuela Pennisi ${ }^{2}$, Giuseppe Grosso ${ }^{1}$, Marco Vacante ${ }^{3}$, Salvatore Salomone ${ }^{1}$, \\ Filippo Drago $^{1}$, Michele Malaguarnera ${ }^{1}$, Erdogan Ozyalcin ${ }^{3}$, Massimo Motta ${ }^{3}$, Valentina Raciti ${ }^{3}$, \\ Mariano Malaguarnera ${ }^{3}$
} ${ }^{1}$ International PhD Programme in Neuropharmacology, University of Catania, Catania, Italy; ${ }^{2}$ Department of Neurosciences, Univer-
sity of Catania, Catania, Italy; ${ }^{3}$ Research Center “The Great Senescence”, Cannizzaro Hospital, University of Catania, Catania, Italy.
Email: " giulia.malaguarnera@live.it

Received May $29^{\text {th }}, 2013$; revised June $30^{\text {th }}, 2013$; accepted July $6^{\text {th }}, 2013$

Copyright (C) 2013 Giulia Malaguarnera et al. This is an open access article distributed under the Creative Commons Attribution License, which permits unrestricted use, distribution, and reproduction in any medium, provided the original work is properly cited.

\begin{abstract}
Background: The employment status of workers with cancer has important implications for impairment of intimate and family relationships and for economic, social and psychological health. The aim of the present study was to evaluate the effect of chemotherapy with capecitabine in patients with colorectal cancer on work productivity and daily activity. Methods: 30 patients with primary diagnosis of stage III colorectal cancer were enrolled for our study. All patients received capecitabine twice daily at a cumulative dose of $2500 \mathrm{mg} / \mathrm{m}^{2}$ on days $1-14$ and repeated on day 22 . Work productivity was determined using the WPAI questionnaire. Results: We observed a significant increase in absenteeism after 1 cycle, after 6 cycles of therapy and at follow-up $(\mathrm{p}<0.001)$. On the other hand, presenteeism, work productivity loss and daily activity impairment, increased after 1 cycle and 6 cycles of therapy, but we could not find statistically different significances. Conclusions: Colorectal cancer diagnosis and treatment are associated with frailty and vulnerability. Chemotherapy with capecitabine may result in negative consequences for job performance.
\end{abstract}

Keywords: Capecitabine; Colorectal Cancer; Work Productivity; Activity Impairment; Absenteeism; Presenteeism

\section{Introduction}

Colon cancer is the third most frequently diagnosed cancer as well as the third leading cause of cancer mortality in men and women in the USA [1]. The incidence of colon cancer has not changed a lot in recent time but agestandardized mortality has improved in the last 30 years [2-4]. This improvement is more pronounced in early colon cancer, where management usually consists of surgery followed by adjuvant treatment. Adjuvant treatment is fluoropyrimidine based, and it has now become a standard of care in the management of colon cancer. After surgery, the next question always is the need for adjuvant treatment and also the choice of chemoterapeutic agent. The goal of adjuvant therapy is to eradicate occult micrometastases present at time of surgery therapy increasing the cure rate. Recent study suggested that non curative resection of asymptomatic colorectal primary tumors may prolong survival in patients with metastatic colon cancer [5]. However another study concluded that initial che-

${ }^{*}$ Corresponding author. motherapy should be started with resection of the primary tumor reserved for the small proportion of patients who develop major complications from the primary tumor because resection of an asymptomatic primary tumor provides only minimal palliative benefits [6]. Capecitabine is an oral fluoropyrimidine, which is converted to 5 -fluorouracil (5-FU), preferentially at the tumor site by a sequential three enzyme pathway. Capecitabine is an effective well tolerated convenient treatment for patients with colorectal cancer. Work is often related to having a purpose in life, a sense of contributing, a distraction, and even one's self esteem. Research related to work disability indicates that work outcomes in those at work with various chronic health problems are influenced by a pattern of factors within the individual environment and society that may also be operational among survivors of cancer [7]. The employment status of workers with cancer has important implications for impairment of intimate and family relationships and for economic, social and psychological health. The aim of the present study was to evaluate the effect of chemotherapy with capecitabine in 
patients with colorectal cancer on work productivity and daily activity.

\section{Methods}

Between January 2011 and December 2012, colorectal patients receiving curative resection were recruited for postoperative adjuvant oral chemotherapy with capecitabine. The study protocol was approved by the Institutional Review Board. Written informed consents were obtained from all partecipants. After 8 weeks of surgical resection, 30 patients with primary diagnosis of stage III colorectal cancer were enrolled for our study. Further eligibility criteria included the following:

1) Age 20 to 50 years; 2) Eastern Cooperative Oncology Group performance status of 0 or 1 ; 3) Adequate hematological function (absolute leukocyte count 4000 to 12,000 leukocytes $/ \mathrm{mm}^{3}$; neutrophil count 2000 neutophils $/ \mathrm{mm}^{3}$ or more, and platelets $100,000 / \mathrm{mm}^{3}$ or more) hepatic function (transaminases 2.5 times or less the upper limit of normal and serum bilirubin $2.0 \mathrm{mg} / \mathrm{dl}$ or less) and renal function (serum creatinine below the upper limit of normal); 4) Ability to take oral medication. Patients were excluded if they had any of following: history of severe drug allergies, interstitial pneumonitis or pulmonary fibrosis, several pleural effusion or ascites, active infection, diarrhea or serious uncontrolled comorbilities or medical conditions. Patients were also excluded if they were participating in another trial, pregnant, breast-feeding, unwilling to use effective contraception or had a medical condition or concomitant illness that might impair protocol compliance. Patients had received no prior chemotherapy. Capecitabine was given twice daily at a cumulative dose of $2500 \mathrm{mg} / \mathrm{m}^{2}$ on days $1-14$ and repeated on day 22. The total daily dose was divided into two equal amounts and given roughly $12 \mathrm{~h}$ apart and within 30 min after a meal, usually breakfast and dinner. Baseline assessment were medical history, clinical examination, complete haematology with differential leucocyte count, clinical chemistry including coagulation parameters, tumour markers CEA and CA 19-9, chest radiography and computed tomographic scans of the abdomen, pelvis and chest before starting treatment at baseline.

\subsection{Laboratory Exams}

A complete routine chemistry including red cell count, hemoglobin, white cell count, platelets, prothrombin time, fasting plasma glucose, insulin, C-reactive protein, blood urea nitrogen, serum creatinine, bilirubin, ALT, aspartate aminotransferase, alkaline phosphatase, $\gamma$-glutamil transpeptidase, and creatin phosphokinase levels was performed at every medical visit. All patients were included in the safety and efficacy analyses. The severity of the adverse effects was evaluated according to the National Cancer
Institute Common Toxicity Criteria (NCI-CTC) version $2.0[8]$.

\subsection{WPAI (Work Productivity and Activity Impairment)}

Work productivity was determined using the WPAI questionnaire. Patients reported the number of actual hours worked, hours missed due to chemotherapy, as well as the effect on productivity while working and doing regular activities during the past 7 days. The WPAI was selfadministered and consisted of four questions that elicited employment status. Scores for abseteeism, presenteeism, overall work productivity loss and impairment in regular (non work) daily activities, such as work around the house, shopping, child care, exercising, studying, were derived as follows: Absenteeism $=$ hours missed/hours missed + hours worked; Presenteeism $=$ scale score/10; Work productivity loss $=$ absenteeism + (hours worked $\times$ presenteeism); Daily activity impairment $=$ scale score/10. Score were transformed into percentage with higher percentages indicating greater work impairment, lower productivity and daily activity impairment.

\subsection{Statistical Analysis}

Results are expressed as means $+/-$ standard deviations. Comparisons of quantitative data were made using the Student's t-test or Mann-Whitney test. Qualitative data were analyzed using the chi-square test. A p value of < 0.05 was considered as indicating a statistically significant difference. All data management and statistical calculations were performed using SPSS 15.0 statistical package (Chigago, IL).

\section{Results}

Patients' characteristics at baseline are reported in Table 1. There were not significant differences between groups at baseline with respect to sex, age, BMI, stage of cancer, number of blue or white collars. As regards WPAI score, colorectal patients treated with capecitabine showed significant increase in absenteeism after 1 cycle $(p<0.001)$ and after 6 cycles of therapy $(\mathrm{p}<0.001)$. We observed the increase in absenteeism also after three months follow up $(\mathrm{p}<0.001)$. On the other hand, presenteeism, work productivity loss and daily activity impairment increased after 1 cycle and 6 cycles of therapy, but we could not find statistically different significances (Table 2). Adverse events after 1 month chemotherapy included gastrointestinal toxicity: $2(6 \%)$ patients had nausea, $1(3 \%)$ diarrhoea, 3 mucositis $(10 \%), 1$ stomatitis (3\%), 1 abdominal pain $(3 \%)$ and 1 proctitis $(3 \%)$ and higher rates of hand-foot skin reactions (10 patients, $33 \%) .8$ patients showed fatigue (26\%) (Table 3). After 6 month therapy we observed the following adverse events: 
Table 1. Patients' characteristics at baseline.

\begin{tabular}{ccc}
\hline Parameter & & \\
\hline Sex & Male & Female \\
$\mathrm{N}$ & 18 & 12 \\
Age (years) Range & $28-48$ & $32-50$ \\
Heart rate (beats per minute) & 84 & 88 \\
SBP (mmHg) & $138 \pm 12$ & $131 \pm 14$ \\
DBP (mmHg) & $81 \pm 7$ & $84 \pm 6$ \\
Smokers/no Smokers & $12 / 6$ & $5 / 7$ \\
BMI (kg/m ${ }^{2}$ ) & $26.8 \pm 4.2$ & $24.4 \pm 4.1$ \\
Stage of cancer & & \\
IIIB & 10 & 7 \\
IIIC & 8 & 5 \\
Blue collars (manual labourers) & 11 & 3 \\
White collars (non manual/office & 7 & 9 \\
labourers) & & \\
\hline
\end{tabular}

Table 2. WPAI score in patients with colorectal cancer (mean \pm SD).

\begin{tabular}{|c|c|c|c|c|}
\hline & Baseline & $\begin{array}{l}\text { After } 1 \text { cycle } \\
\text { treatment }\end{array}$ & $\begin{array}{c}\text { After } 6 \text { cycles } \\
\text { treatment }\end{array}$ & Follow-up \\
\hline Absenteeism & $4.1 \pm 3.7$ & $4.4 \pm 4.8^{* * *}$ & $4.9 \pm 6.4^{* * *}$ & $4.5 \pm 6.7^{* * *}$ \\
\hline Presenteeism & $31.8 \pm 12.4$ & $33.6 \pm 13.9^{*}$ & $35.8 \pm 14.2^{*}$ & $32.6 \pm 13.1^{*}$ \\
\hline $\begin{array}{c}\text { Work } \\
\text { productivity loss }\end{array}$ & $31.4 \pm 13.5$ & $36.4 \pm 14.2^{*}$ & $37.8 \pm 14.5^{*}$ & $34.6 \pm 13.9^{*}$ \\
\hline $\begin{array}{l}\text { Daily activity } \\
\text { impairment }\end{array}$ & $44.1 \pm 16.9$ & $47.2 \pm 17.2^{*}$ & $48.2 \pm 18.1^{*}$ & $45.9 \pm 17.4^{*}$ \\
\hline
\end{tabular}

4 patients with nausea (13\%), 3 with vomiting (10\%), 3 with diarrhoea $(10 \%), 2$ with mucositis $(6 \%), 3$ stomatitis $(10 \%), 3$ abdominal pain $(10 \%)$ and 1 proctitis $(3 \%)$. Moreover hand-foot skin reactions (17 patients, 56\%) and fatigue were observed (19 patients, 63\%) (Table 3).

\section{Discussion}

The aim of this study was to examine the possible effects of chemotherapy stress on work ability. Six cycles of capecitabine were received by all treated patients; with the exception of gastrointestinal toxicity and higher rates of hand-foot skin reactions, capecitabine was well tolerated [9] (Table 3). The improvements of treatment adherence and the low toxicity permitted our patients to resume their work again. If work stress is becoming too high this may result in negative consequences for job performance and possibly the development of diseases. Cancer diagnosis and treatment are associated with frailty and vulnerability $[10,11]$. Reduced work productivity is not necessarily attributed to a chronic health condition. When work productivity is affected by reduced performance due to a health problem, it is often referred
Table 3. Toxic effects in treated patients according to NCICTC.

\begin{tabular}{ccccc}
\hline & \multicolumn{2}{c}{$\begin{array}{c}\text { After 1 month } \\
\text { chemotherapy }\end{array}$} & \multicolumn{2}{c}{$\begin{array}{c}\text { After } \mathbf{6} \text { months } \\
\text { chemotherapy }\end{array}$} \\
\hline & $\begin{array}{c}\text { Grade } \\
\mathbf{1} \text { - 2 }\end{array}$ & $\begin{array}{c}\text { Grade } \\
\mathbf{3 ~ - ~ 4 ~}\end{array}$ & $\begin{array}{c}\text { Grade } \\
\mathbf{1 ~ - ~ 2 ~}\end{array}$ & $\begin{array}{c}\text { Grade } \\
\mathbf{3} \text { - 4 }\end{array}$ \\
\hline Laboratory & & & & \\
Lowered & & & & \\
haemoglobin & 1 & 0 & 2 & 0 \\
Lowered leucocytes & 0 & 0 & 2 & 0 \\
Lowered platelets & 0 & 0 & 1 & 0 \\
Raised creatinine & 0 & 0 & 0 & 0 \\
Raised bilirubin & 0 & 0 & 0 & 1 \\
Gastrointestinal & & & & \\
Nausea & 2 & 0 & 4 & 0 \\
Vomiting & 0 & 0 & 2 & 1 \\
Diarrhoea & 1 & 0 & 2 & 1 \\
Mucositis & 2 & 1 & 1 & 1 \\
Stomatitis & 0 & 1 & 1 & 2 \\
Abdominal pain & 1 & 0 & 2 & 1 \\
Proctitis & 1 & 0 & 1 & 0 \\
Others & & & & \\
Fatigue & & & & \\
Anorexia & 6 & 2 & 14 & 5 \\
Alopecia & 1 & 1 & 2 & 0 \\
Hand-foot skin & 0 & 0 & 0 & 0 \\
reaction & 6 & 4 & 14 & 3 \\
\hline
\end{tabular}

to as presenteeism. It has been demonstrated that social costs are not only related to absenteeism, but to presenteeism as well $[12,13]$. It has been found that health conditions increase work-related absences (absenteeism) and/ or decrease productivity while at work (presenteeism), creating a substantial economic burden on industry [14, 15]. Studies have found that presenteeism leads to greater productivity loss than absenteeism [16]. The costs related to presenteeism might even exceed the costs of absenteeism [17]. Although presenteeism is described as an important factor for productivity loss, it has been observed that workers with a chronic health condition perform well being at work $[18,19]$. Reduced work performance due to health problems is not desiderable, but the alternative of work absence may be even worse, reflected by declining return to work perspectives, as the length of work absence increases [20]. Work productivity represents a well-being indicator that stimulates social inclusion and reduces exclusion such as economy, employment, health housing and social participation [21]. Many participants experienced their work as being a place for healing and recovering. They indicated that work increased the mental and physical well-being. In their work participants found recognition and approval, self-realization and selfrespect. Work plays for many patients an important role in the psychological treatment; in fact job satisfaction was often stated as a strong motivator for social status and for social contacts. We think that cancer patients should be encouraged to resume their activities as soon 
as possible, especially when adverse events are few and tolerable. In some patients we observed a persistent handfoot skin reaction. This symptom was mostly presented in blue collars, while fatigue was presented in both blue and white collars. Although most of colorectal patient were able to work, lower levels of productivity, lower work ability and reduced job retention have been reported. An adequate supportive therapy of fatigue [22-24] could increase work productivity and health-related quality of life. Future studies are needed to investigate the relation among job, cancer, and related cancer treatment, and develop innovative approaches at the workplace to address these areas realistically and head on.

\section{Acknowledgements}

GM, GG, MiM were supported by the International $\mathrm{PhD}$ programme in Neuropharmacology, University of Catania. The authors declare that they have no competing interests.

\section{REFERENCES}

[1] R. L. Siegel, E. M. Ward and A. Jemal, "Trends in Colorectal Cancer Incidence Rates in the United States by Tumor Location and Stage, 1992-2008," Cancer Epidemiology, Biomarkers \& Prevention, Vol. 21, 2012, pp. 411-416. doi:10.1158/1055-9965.EPI-11-1020

[2] D. Hayne, R. S. Brown, M. McCormack, M. J. Quinn, H. A. Payne and Babb, "Current Trends in Colorectal Cancer: Site, Incidence, Mortality and Survival in England and Wales," Clinical Oncology: A Journal of the Royal College of Radiologists, Vol. 13, No. 6, 2001, pp. 448-452.

[3] M. Uccello, G. Malaguarnera, F. Basile, V. D’Agata, M. Malaguarnera, G. Bertino, M. Vacante, F. Drago and A. Biondi, "Potential Role of Probiotics on Colorectal Cancer Prevention," BMC Surgery, Vol. 12, Suppl 1, 2012, p. S35. doi:10.1186/1471-2482-12-S1-S35

[4] A. Biondi, G. Grosso, A. Mistretta, S. Marventano, C. Toscano, S. Gruttadauria and F. Basile, "LaparoscopicAssisted versus Open Surgery for Colorectal Cancer: Short- and Long-Term Outcomes Comparison," Journal of Laparoendoscopic \& Advanced Surgical Techniques, Vol. 23, No. 1, 2013, pp. 1-7. doi:10.1089/lap.2012.0276

[5] A. Eisenberger, R. L. Whelan and A. I. Neugut, "Survival and Symptomatic Benefit from Palliative Primary Tumor Resection in Patients with Metastatic Colorectal Cancer: A Review," International Journal of Colorectal Disease, Vol. 23, No. 6, 2008, pp. 559-568. doi:10.1007/s00384-008-0456-6

[6] M. G. Scheer, C. E. Sloots, G. J. van der Wilt and T. J. Ruers, "Management of Patients with Asymptomatic Colorectal Cancer and Synchronous Irresectable Metastases," Annals of Oncology, Vol. 19, No. 11, 2008, pp. 1829-1835. doi:10.1093/annonc/mdn398

[7] G. Pransky, R. Gatchel, S. J. Linton and P. Loisel, "Improving Return to Work Research," Journal of Occupa- tional Rehabilitation, Vol. 15, No. 4, 2005, pp. 453-457. doi:10.1007/s10926-005-8027-y

[8] National Cancer Institute Common Toxicity Criteria (NCI-CTC), Version 2.0, DCTD, NCI, NIH, DHHS, March 1998.

[9] R. D. Hofheinz, V. Heinemann, L. F. von Weikersthal, R. P. Laubender, D. Gencer, I. Burkholder, A. Hochhaus and S. Stintzing, "Capecitabine-Associated Hand-Foot-Skin Reaction Is an Independent Clinical Predictor of Improved Survival in Patients with Colorectal Cancer," British, Journal of Cancer, Vol. 107, No. 10, 2012, pp. 16781683. doi:10.1038/bjc.2012.434

[10] M. Malaguarnera, M. Vacante, P. M. Frazzetto and M. Motta, "What Is the Frailty in Elderly? Value and Significance of the Multidimensional Assessments," Archives of Gerontology and Geriatrics Vol. 56, No. 1, 2013, pp. 2326. doi:10.1016/j.archger.2011.09.017

[11] M. Vacante, V. D’Agata, M. Motta, G. Malaguarnera, A. Biondi, F. Basile, M. Malaguarnera, C. Gagliano, F. Drago and S. Salamone, "Centenarians and Supercentenarians: A Black Swan. Emerging Social, Medical and Surgical Problems," BMC Surgery, Vol. 12, Suppl 1, 2012, p. S36. doi:10.1186/1471-2482-12-S1-S36

[12] W. F. Stewart, J. A. Ricci, E. Chee and D. Morganstein, "Lost Productive Work Time Costs from Health Conditions in the United States: Results from the American Productivity Audit," Journal of Occupational and Environmental Medicine, 2003, Vol. 45, 2003, pp. 12341246.

[13] P. Hemp, "Presenteeism: At Work, but Out of It," Harvard Business Review, Vol. 82, No. 10, 2004, pp. 49-58.

[14] R. Guthrie, "The Australian Legal Framework for Stress Claims," Journal of Law and Medicine, Vol. 14, No. 4, 2007, pp. 528-550.

[15] W. N. Burton, G. Pransky, D. J. Conti, C. Y. Chen and D. W. Edington, "The Association of Medical Conditions and Presenteeism," Journal of Occupational and Environmental Medicine, Vol. 46, 2004, pp. 38-45. doi:10.1097/01.jom.0000126687.49652.44

[16] R. Z. Goetzel, S. R. Long, R. J. Ozminkowski, K. Hawkins, S. Wang and W. Lynch, "Health, Absence, Disability, and Presenteeism Cost Estimates of Certain Physical and Mental Health Conditions Affecting US Employers," Journal of Occupational and Environmental Medicine, Vol. 46, 2004, pp. 98-412. doi:10.1097/01.jom.0000121151.40413.bd

[17] J. J. Collins, C. M. Baase, C. E. Sharda, R. J. Ozminkowski, S. Nicholson, G. M. Billotti, R. S. Turpin, M. Olson and M. L. Berger, "The Assessment of Chronic Health Conditions on Work Performance, Absence, and Total Economic Impact for Employers," Journal of Occupational and Environmental Medicine, Vol. 47, No. 6, 2005, pp. 547-557. doi:10.1097/01.jom.0000166864.58664.29

[18] T. I. Van den Berg, S. J. Robroek, J. F. Plat, M. A. Koopmanschap and A. Burdorf, "The Importance of Job Control for Workers with Decreased Work Ability to Remain Productive at Work," International Archives of Occupational and Environmental Health, Vol. 84, No. 6, 2011, 
pp. 705-712. doi:10.1007/s00420-010-0588-1

[19] S. G. Van den Heuvel, G. A. Geuskens, W. E. Hooftman, L. L. Koppes and S. N. Van den Bossche, "Productivity Loss at Work: Health-Related and Work-Related Factors," Journal of Occupational Rehabilitation, Vol. 20, No. 3, 2010, pp. 331-339.

doi:10.1007/s10926-009-9219-7

[20] E. Viikari-Juntura and A. Burdorf, "Return to Work and Job Retention-Increasingly Important Outcomes in Occupational Health Research," Scandinavian Journal of Work, Environment \& Health, Vol. 37, No. 2, 2011, pp. 81-84. doi:10.5271/sjweh.3145

[21] T. Atkinson, B. Cantillon, E. Marlier and B. Nolan, "Social Indicators: The EU and Social Inclusion," Oxford University Press, Oxford, 2002. doi:10.1093/0199253498.001.0001
[22] M. Malaguarnera, M. P. Gargante, E. Cristaldi, V. Colonna, M. Messano, A. Koverech, S. Neri, M. Vacante, L. Cammalleri and M. Motta, "Acetyl L-Carnitine (ALC) Treatment in Elderly Patients with Fatigue," Archives of Gerontology and Geriatrics, Vol. 46, No. 2, 2008, pp. 181-190. doi:10.1016/j.archger.2007.03.012

[23] M. Malaguarnera, L. Cammalleri, M. P. Gargante, M. Vacante, V. Colonna and M. Motta, "L-Carnitine Treatment Reduces Severity of Physical and Mental Fatigue and Increases Cognitive Functions in Centenarians: A Randomized and Controlled Clinical Trial," American Journal of Clinical Nutrition, Vol. 86, 2007, pp. 1738-1744.

[24] M. Malaguarnera, "Carnitine Derivatives: Clinical Usefulness," Current Opinion in Gastroenterology, Vol. 28, No. 2, 2012, pp. 166-176. doi:10.1097/MOG.0b013e3283505a3b 